\title{
DatEthics: Ethical Data-Centric Design of Intelligent Behaviour
}

\author{
Jacky Bourgeois \\ J.Bourgeois@tudelft.nl \\ Delft University of Technology \\ Delft, The Netherlands \\ Jered Vroon \\ J.H.Vroon@tudelft.nl \\ Delft University of Technology \\ Delft, The Netherlands
}

Aaron.Ding@tudelft.nl

Delft University of Technology

Delft, The Netherlands

\author{
Ella Peltonen \\ Ella.Peltonen@oulu.fi \\ University of Oulu \\ Oulu, Finland
}

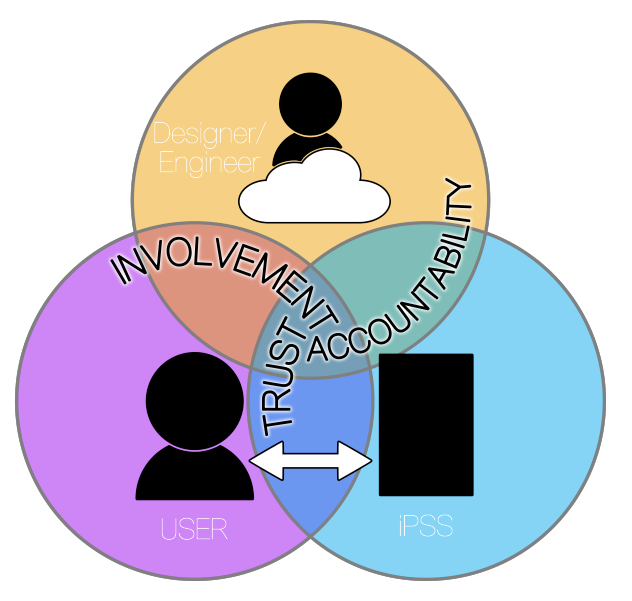

Figure 1: Involvement, Accountability and Trust.

\begin{abstract}
The Internet of Things makes human activity data - what people do, how they move, how they socialise - an abundant resource. However, this rich and intimate perspective on people, which uniquely shape and characterise their behaviours, can have tremendous ethical implication if data is handled irresponsibly. Being personal, contextual and accessible, mobile devices are key facilitators of (ir)responsible collection and use of data. In this workshop, we will use the Future Workshop approach to develop a research agenda towards ethical data-centric design of intelligent behaviours. As part of this approach, we will (1) criticise the current mechanisms and infrastructure to frame ethical challenges, (2) fantasise on futures which support user and designer values, and (3) implement a research agenda for the MobileHCI community to emphasise the barriers to tackle. The outcomes of this workshop will foster ethical research and inspire the MobileHCI community.
\end{abstract}

Permission to make digital or hard copies of part or all of this work for personal or classroom use is granted without fee provided that copies are not made or distributed for profit or commercial advantage and that copies bear this notice and the full citation on the first page. Copyrights for third-party components of this work must be honored. For all other uses, contact the owner/author(s).

MobileHCI '20 Extended Abstracts, October 5-9, 2020, Oldenburg, Germany

(C) 2020 Copyright held by the owner/author(s).

https://doi.org/xx.xxxx/xxxxxxx.xxxxxxx

\section{CCS CONCEPTS}

- Human-centered computing $\rightarrow$ HCI theory, concepts and models.

\section{KEYWORDS}

Ethics; Responsibility; Data-Centric Design; Internet of Things

\section{ACM Reference Format:}

Jacky Bourgeois, Aaron Ding, Jered Vroon, and Ella Peltonen. 2020. DatEthics: Ethical Data-Centric Design of Intelligent Behaviour. In 22nd International Conference on Human-Computer Interaction with Mobile Devices and Services (MobileHCI '20 Extended Abstracts), October 5-9, 2020, Oldenburg, Germany. ACM, New York, NY, USA, 3 pages. https://doi.org/10.1145/3406324.3424589

\section{BACKGROUND}

The development of the Internet of Things (IoT) and machine learning technologies creates opportunities for the design of intelligent behaviours and Product-Service Systems (iPSS). The role of designers is shifting toward the design of systems with learning and evolving behaviours along human's, reinforcing the need of design for 'more than' Human-Centred Design [10]. The use of human activity data - what people do, how they move, how they socialise - brings a vast array of new insights to inform and evaluate the design process of iPSS. In this context, there is a growing need from the design research community to use data as a 'design material' $[1,2,4,5,7,8,13,14]$. 
Mobile devices are a key component of such data-centric design, as they provide a personal, contextual and accessible gateway to data. For instance, they facilitate data collection [15], experience sampling [16], participant recruitment [11] and participant interaction [1]. Rich, intimate data is core to these emerging design methods as they enable valuable knowledge for the design of relevant products and services.

However, personal data is also uniquely shaped and characterised by users in nature. If designers use it irresponsibly, people may not want to share it anymore. While the case of Cambridge Analytica is a notable example [6], irresponsibility might be more subtle [3]. Thus, we need to handle personal data in a responsible and ethical way.

In this workshop, we look at mobile devices as vital ethical links between users and designers in the data mediation. We focus on the role of mobile devices in fostering ethical Data-Centric Design of intelligent behaviours. We aim to characterise these ethical challenges, envision futures that address them and identify the research challenges in order to achieve these futures.

\section{GOAL OF THE WORKSHOP}

The goal of this 1-day workshop is to envision the design of mobile interactions that foster ethical Data-Centric Design of intelligent behaviour. These interactions will be the materialisation of mechanisms that support ethical use of human activity data to better understand the role of mobile platforms in responsible Data-Centric Design of intelligent behaviours. The workshop outcome will take the form of a MobileHCI vision to support ethical Data-Centric Design approaches and a research agenda. We scope the workshop around three core moral values that relates to technology from Value-Sensitive Design [9]. Figure 1 illustrates this dynamic between stakeholders and values.

- Accountability - Referring to the properties that ensures that actions of a person, people, or institution may be traced uniquely;

- Trust - Referring to the expectations that exist between people who can experience good will, extend good will toward others, feel vulnerable, and experience betrayal;

- Involvement - Referring to the engagement of and interaction between stakeholders, which is highlighted as a key component of Value-Sensitive Design projects.

\section{SCHEDULE}

Introduction to the theme and workshop method, round table of the participants and warm-up exercise

3.0.1 Critique Phase. Split into disciplinary groups to generate a deep understanding of the problem, then share disciplinary perspectives in plenary session.

3.0.2 Break.

3.0.3 Fantasy Phase. Split into multi-disciplinary groups to envision futures, then share these ideals in plenary session.

3.0.4 Break

3.0.5 Implementation Phase. Identify the barrier towards ideal futures and formulate a research agenda
3.0.6 Conclusion/Evaluation. Connect participants who want to engage in follow-up work and nurture the community

\section{WORKSHOP STRUCTURE}

It is challenging to envision situations beyond well-established mechanisms, infrastructure, technologies and model already in place. To achieve this goal, we propose a Future Workshop as introduced by Jungk and Muller [12,17]. Future Workshop is an approach for planning and enacting possible futures in five phases - prepare, criticise, fantasise, implement and follow-up - towards a joint proposal for change. The workshop will follow these phases, as the sidebar illustrates a draft schedule of the day.

Prepare This phase is about setting up the theme, who should participate and what methods will be used - in essence, this is the organisational setting of this workshop.

Criticise The second phase involves a divergent and a convergent moment to draw out specific issues and problems in questions in order to establish a critical understanding of the theme. We will split into disciplinary groups for a brainstorm before converging in a plenary session and cluster topics using mind mapping.

Fantasise At this stage, the group diverge and converge again to create utopias, exaggerated pictures of future possibilities. We will encourage participants to form interdisciplinary groups and use fiction triggers as a starting point. The convergence will involve the evaluation of strength and weaknesses of each future, which will be achieve per group through a SWOT analysis.

Implement The fourth step is about merging, tuning and selecting ideas to shape the most achievable future. We will close this stage with clear formulation of a vision statement along a research agenda: an action plan for the MobileHCI community. The expertise from all disciplines will enable to make this plan concrete, realistic and actionable.

Follow-up The final stage is about reporting and monitoring the execution of the action plan. We formulate this process in the section 'Planned Outcomes', focusing on sharing results and nurturing the community.

\section{AUDIENCE}

For this workshop, we envision an interdisciplinary group (e.g. design, HCI, system, philosophy) of 20 participants. This diversity is important for the Future Workshop approach to generate outcomes that are not limited to nor constraint by a single discipline. We will guarantee diverse and interdisciplinary participant group by reaching out various channels and audiences with the participation call, and sending it directly to the identified key researchers in the area.

We will encourage participants from all disciplines, disseminating the call through the relevant mailing lists including HCI, philosophy, social sciences and design as well as through our international networks. In addition, we will actively distribute the call of participation - and later the outcomes of the workshop - in various social media channels, such as Twitter, Facebook, ResearchGate, and LinkedIn.

Our call for participants will invite contributions through a 2page position paper in which participants will express their views, experience and opinions towards ethical Data-Centric design of 
intelligent behaviour. The position papers will be made available for the participants before the workshop and for the wider audience after it as a part of the outcomes.

We will setup up a website to advertise the workshop and communicate about its aim and activities. It will also include our call for participation and provide an overview of our focus area and its background. Links to the position papers and other outcomes of the workshop will also be distributed through the website.

\section{WORKSHOP ORGANISERS}

Jacky Bourgeois (Contact person) is tenure-track Assistant Professor at the Faculty of Industrial Design Engineering, TU Delft. With a background in computer science, he explores the exciting interface between Design and the Internet of Things with a focus on personal data.

Aaron Ding is a tenure-track Assistant Professor in the Department of Engineering Systems and Services at TU Delft and Adjunct Professor (Dosentti) in Computer Science at University of Helsinki. His research focuses on edge computing, distributed AI and datadriven IoT services. He has over 12 years of research experience across EU, UK and USA.

Jered Vroon is Postdoc Social Interaction Dynamics in the Knowledge and Intelligence Design Group, TU Delft. He is fascinated by the various ways in which people attempt to interact with the technology around us, and investigates how we can create artefacts that meaningfully engage in those interactions.

Ella Peltonen is a research scientist with the Center for Ubiquitous Computing, University of Oulu, Finland. Her research focuses on pervasive everyday sensing, edge-native machine learning, and "from data to actions" including ubiquitous recommendation systems and data analytics.

\section{PLANNED OUTCOMES}

We will compile the position papers of the participants into a proceeding accessible on arxiv.org. Through the Future Workshop approach, we will also generate ideas that suggest promising directions for future research. Namely, futures for MobileHCI ethics and challenges to achieve them. We will capture these futures in a MobileHCI vision to support ethical Data-Centric Design approaches and synthesise the challenges into a research agenda. We will share these results on the workshop website and invite participants to co-write this contribution for the MobileHCI'21 conference in order to inspire and foster research on this topic.

Finally, we will convey all participants to a dinner and nurture the community. This workshop is a timely opportunity to take concrete step towards enabling ethical Data-Centric Design through mobile devices. Together, we will decide the communication channels to continue collaboration in various research projects and future workshops, scientific publications, and ACM magazine articles to deliver our message for a larger audience withing the mobile computing and HCI fields.

\section{REFERENCES}

[1] Sander Bogers, Joep Frens, Janne van Kollenburg, Eva Deckers, and Caroline Hummels. 2016. Connected Baby Bottle. In Proceedings of the 2016 ACM Conference on Designing Interactive Systems - DIS '16 (DIS '16). ACM, New York, NY, USA, 301-311. https://doi.org/10.1145/2901790.2901855
[2] Jacky Bourgeois, Stefan Foell, Gerd Kortuem, Blaine A Price, Janet Van Der Linden, Eiman Y Elbanhawy, and Christopher Rimmer. 2015. Harvesting green miles from my roof: an investigation into self-sufficient mobility with electric vehicles. In Proceedings of the 2015 ACM International foint Conference on Pervasive and Ubiquitous Computing. 1065-1076.

[3] Jacky Bourgeois and Gerd Kortuem. 2019. Towards Responsible Design with Internet of Things Data. Proceedings of the Design Society: International Conference on Engineering Design 1, 1 (2019), 3421-3430. https://doi.org/10.1017/dsi.2019.349

[4] Jacky Bourgeois, Janet Van Der Linden, Gerd Kortuem, Blaine A Price, and Christopher Rimmer. 2014. Conversations with my washing machine: an in-thewild study of demand shifting with self-generated energy. In Proceedings of the 2014 ACM International foint Conference on Pervasive and Ubiquitous Computing. 459-470.

[5] Jacky Bourgeois, Janet Van Der Linden, Gerd Kortuem, and Christopher Rimmer. 2014. Using Participatory Data Analysis to Understand Social Constraints and Opportunities of Electricity Demand-Shifting. In 2nd International Conference on ICT for Sustainability (ICT4S 2014). Stockholm, Sweden. https://doi.org/10.2991/ ict4s-14.2014.49

[6] Carole Cadwalladr and Emma Graham-Harrison. 2018. Revealed: 50 million Facebook profiles harvested for Cambridge Analytica in major data breach. The guardian 17 (2018), 22.

[7] Graham Dove and Sara Jones. 2014. Using data to stimulate creative thinking in the design of new products and services. In Proceedings of the 2014 conference on Designing interactive systems. 443-452.

[8] Melanie Feinberg. 2017. A Design Perspective on Data. In Proceedings of the 2017 CHI Conference on Human Factors in Computing Systems (Denver, Colorado, USA) (CHI '17). Association for Computing Machinery, New York, NY, USA, 2952-2963. https://doi.org/10.1145/3025453.3025837

[9] Batya Friedman, Peter H. Kahn Jr., and Alan Borning. 2014. Early engagement and new technologies: opening up the laboratory. Vol. 1. 224-227 pages. https: //doi.org/10.1080/23299460.2014.924240

[10] Elisa Giaccardi and Elisa Giaccardi. 2020. Casting Things as Partners in Design : Toward a More-than-Human Design Practice. In Relating to Things: Design, Technology and the Artificial, Heather Wiltse (Ed.). Number May. Bloomsbury.

[11] Jennifer Jardine, Jonathan Fisher, and Benjamin Carrick. 2015. Apple's ResearchKit: smart data collection for the smartphone era?

[12] Robert Jungk and Norbert Müllert. 1987. Future Workshops: How to create desirable futures. Institute for Social Inventions London.

[13] Chris Speed and Jon Oberlander. 2016. Designing from, with and by Data: Introducing the ablative framework. In Proceedings of the the 50th Anniversary Conference of the Design Research Society.

[14] Fionn Tynan-O'Mahony and Chris Speed. 2015. Listening to an Everyday Kettle: How Can the Data Objects Collect Be Useful for Design Research?. In Participatory Innovation Conference.

[15] Yonatan Vaizman, Katherine Ellis, Gert Lanckriet, and Nadir Weibel. 2018. ExtraSensory App: Data Collection In-the-Wild with Rich User Interface to SelfReport Behavior. Proceedings of the 2018 CHI Conference on Human Factors in Computing Systems - CHI '18 (2018), 1-12. https://doi.org/10.1145/3173574.3174128

[16] Niels van Berkel, Denzil Ferreira, and Vassilis Kostakos. 2017. The Experience Sampling Method on Mobile Devices. ACM Comput. Surv. 50, 6, Article 93 (Dec. 2017), 40 pages. https://doi.org/10.1145/3123988

[17] René Victor Valqui Vidal. 2006. The Future Workshop. In Creative and Participative Problem Solving - The Art and the Science. Chapter 6. 